\title{
Study on reverse technological spillover from outward direct investment
}

\author{
Yao Yao \\ Hangzhou Institute of Service Engineering, Hangzhou Normal University, Hangzhou, 311121, China \\ yyaoexist@163.com
}

Keywords: reverse technological spillover, outward direct investment, innovation, affecting factors

\begin{abstract}
The outward direct investment from developing countries has been growing rapidly. Unlike conventional foreign direct investment motivated by cost reduction or natural resource, the developing countries aim to obtain advanced technology from investing in developed countries. Home country could benefit from reverse technological spillovers from outward direct investment. This paper analyzed factors that affect reverse technological spillover from outward direct investment, include macroeconomic, technological and institutional factors in both home country and host country. Then the paper explored the influences of reverse technological spillovers on innovation in home country. Policy support and strategies to promote international technology transmission is also analyzed. Government policy which facilitate and support technology seeking outward direct investment, and provide a favorable environment for technology transfer, as well as sufficient legal protection in intellectual property, would promote positive reverse technological spillovers.
\end{abstract}

\section{Introduction}

The motivation of outward direct investment is driven by various factors. The classical theories concerning outward direct investment focus on the investment from developed countries into developing countries. Monopoly advantage theory of Stephen Hymer and OLI model by John Dunning, based on outward foreign direct investment practice in the 1960s, consider cost reduction as primary factor driven the firms to invest abroad, and the firms would have advantages over the host country. The marginal industry transfer theory of Kiyoshi Kojima, based on outward direct investment of Japanese firms in the 1970s, also considering lower labor cost in less developed countries as the main reason for Japan to invest overseas and transfer the marginal industries outside the country. As a fact that more developing countries has been participating in outward direct investment, theories such as small scale technology theory and technology localization theory have been explaining the phenomenon of increasing outward direct investment from emerging economies. Technology seeking as motivation plays a crucial role in outward direct investment nowadays. Ranked third in outward direct investment, Chinese corporations is becoming more interested in direct investment overseas, so as to obtain lower cost, market share, natural resources, and more importantly, advanced technology. The destination of outward direct investment from China is mostly into Asia and other emerging economies. However, the investment flow into Northern America, Europe and other developed countries has been growing rapidly. The outward direct investment in advanced economies leads to reverse technological spillovers, which would benefit the technological development of the firm, the industry and home country. This paper will examine the affecting factors and the mechanism of reverse technological spillovers, its interaction with innovation, and coping strategies and promoting policies. The paper is organized as follows: the first part introduces the situation of outward direct investment and reverse technological spillovers; the second part examines the factors affecting reverse technological spillovers in outward direct investment; the third part elaborates the interaction between innovation and reverse technological spillovers; the fourth part provides the policy and strategy to promote reverse technological spillovers; and the last part gives conclusions. 


\section{Affecting factors}

There are various factors affecting the scale and effect of reverse technological spillovers in outward direct investment. This section will examine how the factors influence reverse technological spillovers.

Factors concerning host countries. The general economic growth and macroeconomic development is also important. The overall macroeconomic situation has impact on the productivity growth, and determines the environment for research and development. The density of technological research and development in host country has impact on overseas technology disperse. Generally, in host country, the higher density of research and development, the more attractive for foreign investors which are seeking technological spillovers. The stock asset in research and development in host country is primary variable that affect the scale of reverse technology spillovers. The absorption of technology from host countries from direct investment is largely influenced by the technology level of the host country. Institutional condition in the host country has direct influence on whether a foreign firm could enjoy reverse technological spillover from direct investment. International investment barriers, which have been eliminated or mitigated globally for the past several decades, has increased after international financial crisis. Many developed countries scrutinized foreign investors more seriously, and inclined to not to permit foreign investment in strategic industries. Some countries denied cross-border mergers and acquisitions in high tech industry, such as information technology industry, telecommunication industry. Some countries opposes foreign investment in sensitive industries, such as electrical power, shipping port, hydropower station and exploitation of natural resources. Another factor attributes to reverse technological spillover is human capital in host countries. The level of human capital, and the mobility of technological experts and skilled workers, would be a crucial link in the mechanism of technology transmission.

Factors concerning home countries. The technology absorption ability of the firms in home country determines whether positive reverse technological spillovers exist, and its scale. Technology gap between the home country and the host country is a crucial variable in determining the ability of technology absorption. The home country should be over certain technological development level, so as to have the basic knowledge to learn from the technology in host country. The macroeconomic environment of the home country attributes to the ability to acquirement and application of technology and skills from foreign market while participate in outward foreign direct investment. Sustainable growth in home country would provide the multinational firms a favorable environment to invest, research, production and expansion. The effective exchange rate of home country currency has negative effect on foreign direct investment. The appreciation of domestic currency in home country would lead to more outward direct investment, hence more opportunity to reverse technological spillovers. The financial system of the home country also attribute to the ability to obtain reverse technological spillovers of multinational corporations. Outward direct investment from home country to more advance economy, so as to acquire technology and skills, requires sufficient fund. A sound financial system in home country could provide funds for overseas investment. Particularly, for firms from private sector with less financing resource, financial difficulties may result in failure in investment overseas. Reverse technology spillover from out ward direct investment may only show its effects in the longer term. Without continuous subsequent financial support, the outward direct investment may not have any spillovers even if the performance in the accounts is favorable. Apart from the investment itself, reverse technology spillover requires inputs in research, human capital, training and technology reform. With more diversified financing methods, and support for small and medium sized firms, private sector, start-ups and strategically important industries, more efficient financial resources allocation could boost overseas investment. Another important factor that influences reverse technological spillovers is institutional factor. Institutional environment in home country plays an important role in the outward direct investment behavior of local firms, and their ability to absorb, learn and further develop new technology from foreign market. Regulations in home country, restrictions in overseas investment and the complexity of the approval system, would hamper the development of outward direct investment, and in turn, 
eliminate the opportunities to obtain new technology in global market. The environment of research and innovation in domestic market in the home country is crucial in the absorption ability of the local firms.

\section{Reverse technological spillover and innovation}

The influence of reverse technological spillover on innovation. Theoretically, reverse technological spillover from outward direct investment would have positive effects on the innovation of the industry in home country. Some of the corporations participated in outward direct investment are driven by the motivation of obtaining advanced technology and skills from host country. This is particularly the case with corporations from emerging economies which are investing in advance economies. Technology and other intellectual property obtained in outward direct investment from the host country, would contribute to the research and development of the corporations in the home country, and raise the general technology level in the industry in home country, driven the development of the related industries, and benefit the overall technology level and innovation ability of the home country. The effect of reserve technological spillovers on home country innovation could be in different ways. Through technology transmission, technology absorption, and technology interaction, outward direct investment could promote innovation.

China's outward direct investment and innovation. At the macro level, the reverse technological spillover in outward direct investment in China is rather little. Some studies argue that outward direct investment of Chinese firms has no effect on innovation, or even seen a negative effect. One of the reasons is that though scale and scope of outward direct investment from China is in expansion, the investment are mostly flow into emerging economies in Asia and Latin America. The motivation of investment is largely lie on cost reduction and natural resource. Despite its rapid growth, investments in high tech industries take up only a small proportion in overall investment. Moreover, the firms participated in technology seeking motivated outward direct investment would likely to be in private sector, which do not have access to the financial support and policy support such as large state owned corporations. The human resource, legal and intellectual property regulations in host countries could also hinder the reverse technology spillovers. However, more and more Chinese corporations started to set up overseas research center in advanced countries. Huawei Technology, one of the information technology giants, has established several research centers in North America and Europe. In the impact of outward direct investment on innovation, regional difference is obvious. In eastern China, with higher level of technology and better economic development, some firms enjoy the benefit from learning, obtaining and transformation of new technology from overseas. While firms in less developed areas could not absorb technology from global market. With larger technological gap, the less developed area may not been able to learn, imitate, much less catch up with new technology from advanced economies.

\section{The policy and strategies}

The government of the home country in outward foreign direct investment could provide guidance and services. To promote and facilitate technology seeking outward direct investment and reverse technological spillovers, government could take measures to promote the development of domestic multinational corporations, to encourage outward direct investment into developed countries in North America and Europe, to enhance legal protection of intellectual property, and to provide a generally favorable environment to introduction of technology from overseas direct investment. The government could also act as a medium in facilitating international cooperation and communication in technology development. Policies in promoting innovation could be combined with the policies designed to promote technological overseas direct investment. The structure of policies to promote outward direct investment should be more focused on the quality rather than the quantity of overseas investment. Science and technology policies could add in technology absorption and catch up from overseas market. As for the participants in outward direct investment, more inputs into research and 
development, promote their technology level, cultivate a more skilled staff team, is crucial for the corporations to benefit from reverse technological spillover. More investment in technology research and development, introducing more expert in science and technology, would attribute to technology upgrade of the corporation, promote initiative in overseas technology seeking direct investment. Meanwhile, enhance the ability of independent research, could also help in a more smooth process in technological absorption, imitation and technology catch up.

\section{Conclusions}

The scale and scope of outward direct investment from China is expanding. Motivated by technology seeking, more firms invested in developed countries, aiming to obtain advanced technology. For steady and sustainable economic growth in the future, China requires structural reform, industrial transformation and upgrading, emphasizes on technology innovation. The advanced technology could be the result of independent research or absorbed from foreign market.This paper analyzed factors that affect the existence and scale of reverse technological spillover from outward direct investment, include macroeconomic, technological and institutional factors that categorized into home country factors and host country factors. Then the paper explored the influences of reverse technological spillovers on innovation in home country. Policy support and strategies to promote international technology transmission is also analyzed. While research and development level, human capital and economic growth in host country have positive effect on reverse technological spillover; the technology gap is negatively related to reverse technological spillover. A sound financial system and favorable institutional environment in home country would also attribute to positive spillovers. Whether outward direct investment would increase productivity and promote innovation is unclear, the result may differ across districts. Government policy which facilitate and support technology seeking outward direct investment, and provide a favorable environment for technology transfer, as well as sufficient legal protection in intellectual property, would promote positive reverse technological spillovers.

\section{Acknowledgement}

This study is supported by the Natural Science Foundation of Zhejiang Province, Research on financial time series data mining, LQ15F020013.

\section{References}

[1] V. Z. Chen, J. Li, D. M. Shapiro, International reverse spillover effects on parent firms: Evidences from emerging-market MNEs in developed markets, European Management Journal, 30 (2012), 204-218.

[2] A. Fujimori, T. Sato, Productivity and technology diffusion in India: The spillover effects from foreign direct investment, Journal of Policy Modeling, 37 (2015), 630-651.

[3] M. Lin, Y. K. Kwan, FDI technology spillovers, geography, and spatial diffusion, International Review of Economics \& Finance, 43 (2016), 257-274.

[4] C. C. Wang, A. Wu, Geographical FDI knowledge spillover and innovation of indigenous firms in China, International Business Review, 25 (2016), 895-906.

[5] S.M.S. Krammer, Do good institutions enhance the effect of technological spillovers on productivity? Comparative evidence from developed and transition economies, Technological Forecasting and Social Change, 94 (2015), 133-154.

[6] W. Zhao, L. Liu, T. Zhao, The contribution of outward direct investment to productivity changes within China, Journal of International Management, 16 (2010), 121-130. 
[7] S.M.S. Krammer, Assessing the relative importance of multiple channels for embodied and disembodied technological spillovers,Technological Forecasting and Social Change, 81 (2014), 272-286.

[8] P. Heiden, C. Pohl, S. Mansor, J. Genderen, Necessitated absorptive capacity and metaroutines in international technology transfer: A new model, Journal of Engineering and Technology Management, 41 (2016), 65-78.

[9] J. Li, R. Strange, L. Ning, D. Sutherland, Outward foreign direct investment and domestic innovation performance: Evidence from China, International Business Review, 25 (2016), 1010-1019. 